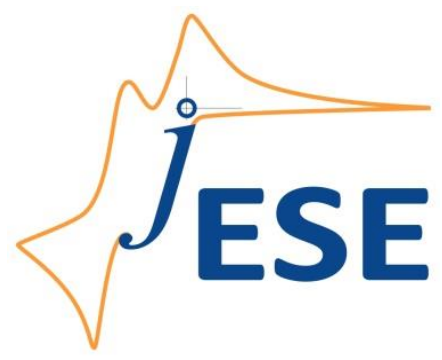

Open Access : : ISSN 1847-9286

www.jESE-online.org

Original scientific paper

\title{
Application of the quadratic logistic differential equation for the rationalization of methanol electrooxidation dynamics
}

Hossein Heli ${ }^{\boxplus}$, Fereydoon Gobal*

Nanomedicine and Nanobiology Research Centre, Shiraz University of Medical Sciences, Shiraz, Iran

*Department of Chemistry, Sharif University of Technology, Tehran, Iran

Corresponding author: hheli7@yahoo.com, heli@sums.ac.ir,Tel/Fax: +98 713612 22 25,6

Received: September 22, 2016; Revised: November 24, 2016; Accepted: November 25, 2016

\begin{abstract}
The electrooxidation of methanol in both acidic and alkaline media on poly-crystalline platinum under the regime of cyclic voltammetry is analyzed by application of quadratic logistic equation. The current-charge curves in the anodic cycles fit the logistic differential equation reasonably well and are accounted on the basis of the non-linearity of the kinetics and the effect of positive feedback. In the reverse cycle however, no fit is observed, presumably due to the lack of correlation between the net faradaic current and the surface charge of adsorbates.
\end{abstract}

\section{Keywords}

Logistic differential equation; Feedback; Methanol electrooxidation; Electrocatalysis; Fuel cell

\section{Introduction}

Methanol is regarded as an attractive fuel in the fast-emerging fuel cell industry, but despite extensive electrocatalytic studies [1-4], there are major problems and kinetic limitations to its direct employment. Ample information concerning the kinetics and mechanism and reactive surfaces, as well as stable bulk intermediates involved in the methanol electrooxidation reaction (MEO) exist in the literature [5,6]. For further amplification of findings, studies on the non-linearity, multi-stability, and chaotic behavior of MEO are essential. MEO process is described very well by mathematical methods and modeling studies due to: (i) high quality data that either exist or can easily be obtained in a using relatively straight forward electrochemical measurements; (ii) the important factors, electrochemical or else, can easily be controlled and the responses of the system measured; (iii) multitude of correlations can be visualized in electrochemical measurements and in the present context, the current-charge ( $\mathrm{d} Q / \mathrm{d} t$ vs. $Q$ ) dependency seems to be most suitable. The quadratic 
logistic differential equation (QLE) [7-9] in the form of a difference for mapping [10,11] in the normalized form

$$
\mathrm{d} x / \mathrm{d} t=r x(1-x)
$$

describes the effects of feedback, as well as the effect of parameter $r$ on the value of normalized variable $x(0<x<1)$. On the one hand, Eq. (1) is associated with the intrinsic rate of the process under study. On the other hand, it describes non-linearity and chaos in the dynamics of the process in a simple way, by illustrating these phenomena through working with only one variable. For $r>3$ the value of $x$ progressively turns to a periodic motion and for $3.5699 \ldots<r<4$ it behaves chaotically.

Eq.-(1) can be alternatively written as:

$$
x_{i+1}=r x_{i}\left(1-x_{i}\right)
$$

where consecutive values of $x$ can be worked out on the basis of a set of initial values [12], while the term (1-x) surely guarantees non-linear effects.

In the present study, a new approach is presented in an order to understand the methanol electrooxidation dynamics, both in acidic and alkaline solutions. This approach is based on the quadratic logistic equation that has been used extensively, as an example of simple equation with only one degree of freedom that illustrates occurrence of bifurcation and chaos in dynamical systems [9].

\section{Experimental}

\section{Materials and methods}

Sodium hydroxide, sulfuric acid and methanol used in this work were of reagent grade of Merck origin and used without further purifications. All solutions were prepared with distilled water. Electrochemical experiments were carried out in a conventional three-electrode cell with platinum wire, exposing the surface area of $0.25 \mathrm{~cm}^{2}$, as the working electrode and its potential monitored against the saturated $\mathrm{Ag} / \mathrm{AgCl}$ reference electrode. A large platinum sheet was used as the counter electrode. All electrochemical measurements were performed at room temperature. The cell was powered by a $\mu$-Autolab potentiostat/galvanostat run by computer through the GPES software. Charges were calculated by integrating the area under voltammograms left after correction for the background. All potential values were further converted and reported relative to the normal hydrogen electrode.

\section{Results and discussion}

Figure 1 shows typical cyclic voltammograms (CV) representing MEO on polycrystalline Pt in $0.5 \mathrm{M}$ sulfuric acid (a) and $0.5 \mathrm{M}$ sodium hydroxide (b) solutions. In both systems, methanol concentration and potential sweep rates were $0.1 \mathrm{M}$ and $20 \mathrm{mV} \mathrm{s}^{-1}$, respectively. The large peak observed in the anodic half cycle is believed $[13,14]$ to be due to the oxidative stripping of protons from the adsorbed methanol molecules to form strongly adsorbed intermediates of $\mathrm{COH}_{\text {ads }}$ and $\mathrm{CO}_{\text {ads. }}$. Their subsequent reaction with $\mathrm{OH}_{\text {ads }}$ (or alternatively with $\mathrm{OH}_{\text {aq }}^{-}$) at higher over-potentials yields the final oxidation products $[3,15]$. Carbon dioxide or carbonates are the final products and the surface remains largely covered by $\mathrm{OH}_{\text {ads }}$ species at the end of an anodic half-cycle. Desorption of this species in the reverse potential sweep creates vacant active sites and promotes continuation of methanol oxidation with a spurt of anodic current until the potential became so cathodic that neither oxidative stripping, nor the follow-up reactions can occur to any significant extent. Higher 
anodic currents met in the alkaline solution is due to abundance of available hydroxide ions. It has been suggested that formation of $\mathrm{OH}_{\text {ads }}$ from alkaline solutions is more kinetically favored over that from acidic media by energy roughly corresponding to that of water ionization $[16,17]$. Surely, the higher currents attainable in alkaline media are off-set by formation of carbonates, which is undesirable, as far as the fuel cell industry is concerned [18].

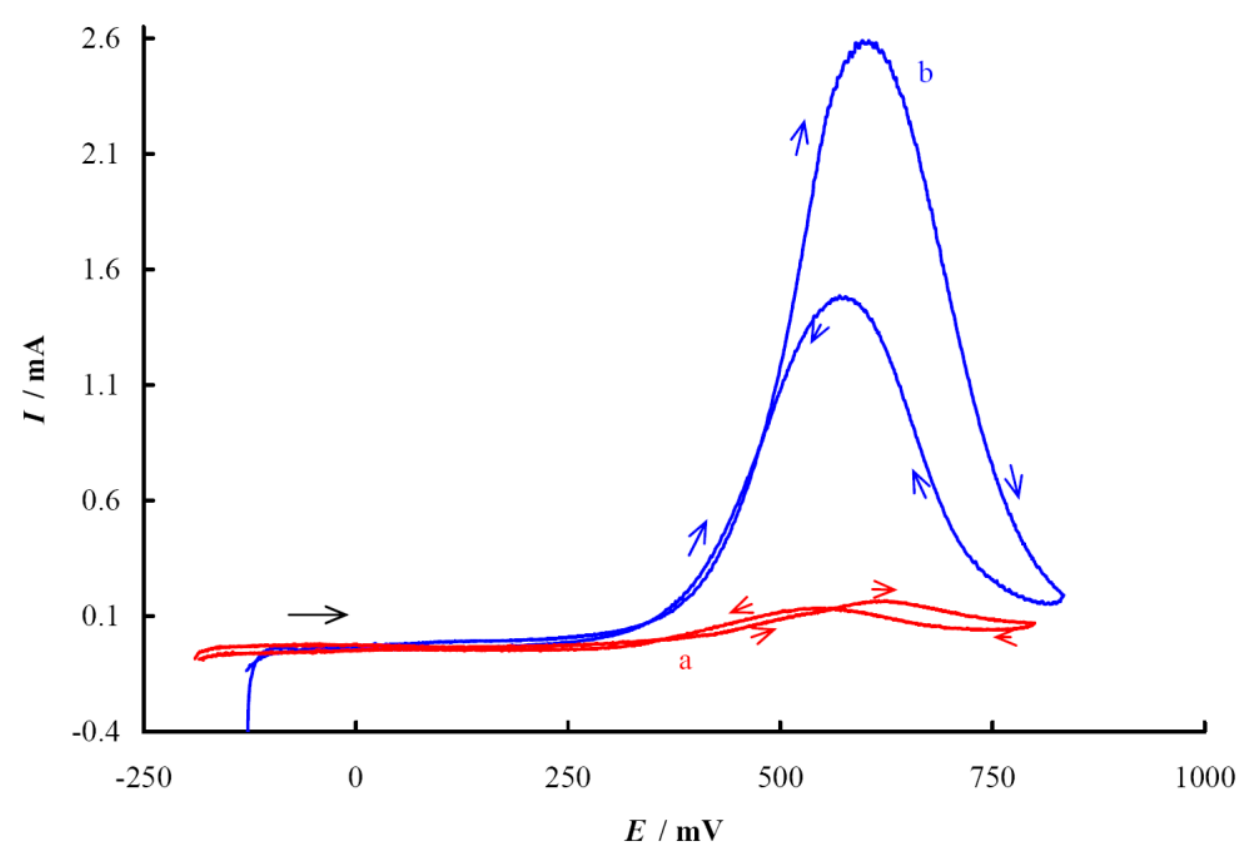

Figure 1. Typical cyclic voltammograms representing MEO on polycrystalline Pt in $0.5 \mathrm{M}$ sulfuric acid (a) and $0.5 \mathrm{M}$ sodium hydroxide (b) solutions comprised $0.1 \mathrm{M}$ methanol. Potential sweep rates are $20 \mathrm{mV} \mathrm{s}^{-1}$.

Figure 2a illustrates the galvanostatic scan of MEO on Pt electrode. Current sweep rate was $10 \mu \mathrm{A} \mathrm{s}^{-1}$. A hard transition from oscillatory to stationary behavior is seen at high current, while a soft supercritical Hopf bifurcation is discerned at low current. The potential-time series of methanol electrooxidation on Pt electrode with the anodic current step of $300 \mu \mathrm{A}$ is represented in Figure $2 \mathrm{~b}$. After approximately $3 \mathrm{~s}$, a periodic pattern was observed, which was followed by an aperiodic oscillation as an indication of chaotic state.

In the mechanistic front, it is believed that the current at low potentials is controlled by the oxidative decomposition of adsorbed methanol and formation of $\mathrm{COH}_{\text {ads }}$ and $\mathrm{CO}_{\text {ads }}$ species [19-21]. It is conceivable [21] that three adjacent surface sites are initially required for the formation of $\mathrm{COH}_{\text {ads }}$ according to the following mechanism:

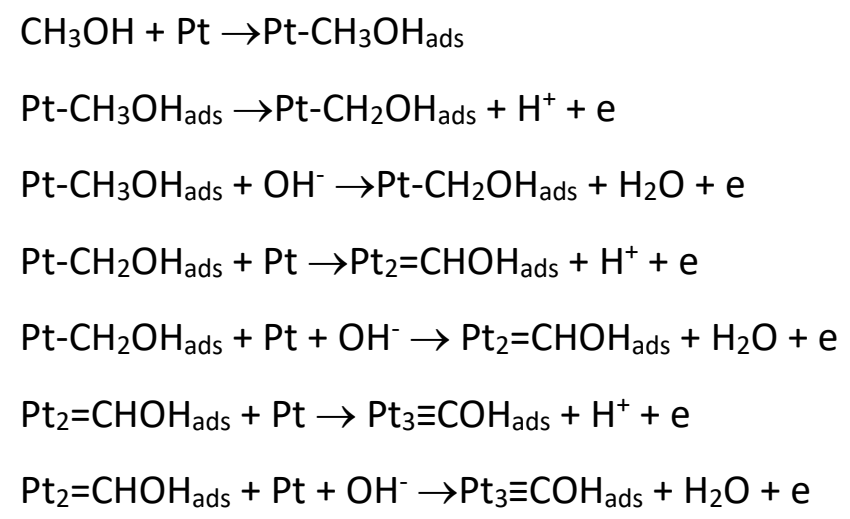



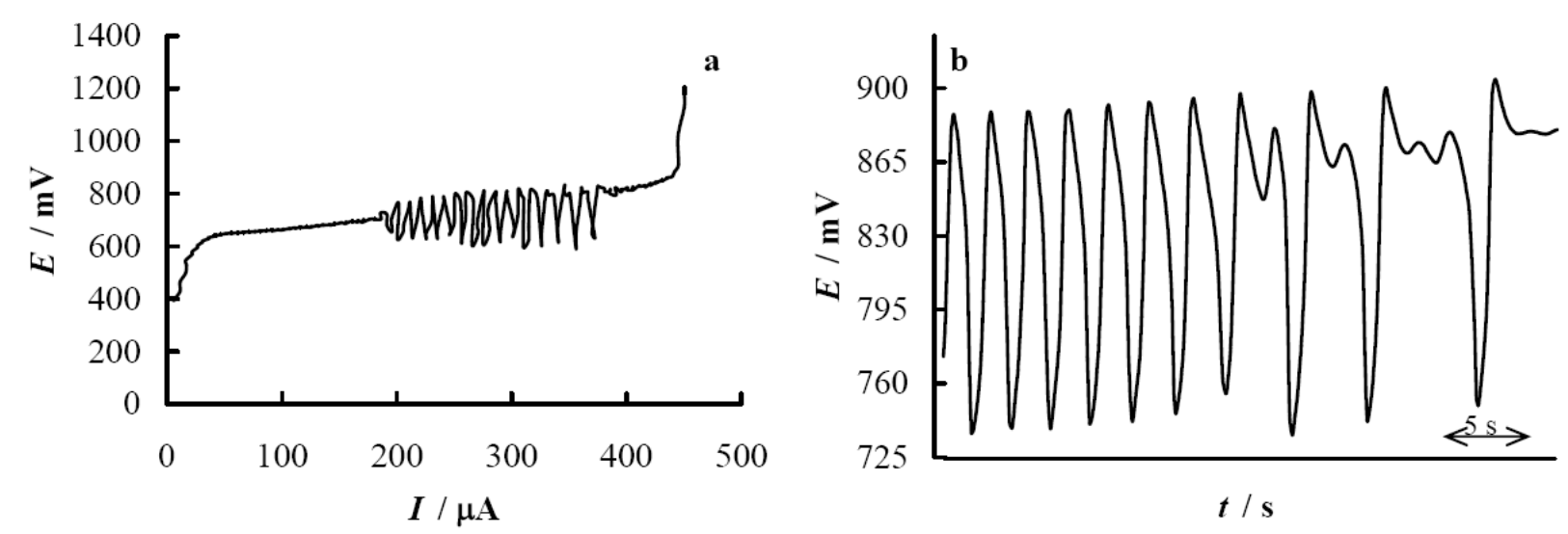

Figure 2. (a) Onset of sustained potential oscillation in the galvanostatic scan on polycrystalline Pt in $0.5 \mathrm{M}$ sulfuric acid comprised in $1 \mathrm{M}$ methanol. Current sweep rate is $10 \mu \mathrm{A} \mathrm{s} \mathrm{s}^{-1}$,

(b) Potential-time response of methanol electrooxidation on polycrystalline Pt in $0.5 \mathrm{M}$ sulfuric acid comprised $1 \mathrm{M}$ methanol. Current step is $300 \mu \mathrm{A}$.

Up to two of these sites, however, are subsequently liberated in the course of reactions yielding bridged or linearly bonded CO species [14]:

$$
\begin{aligned}
& \mathrm{Pt}_{3} \equiv \mathrm{COH}_{\mathrm{ads}} \rightarrow \mathrm{Pt}_{2}=\mathrm{CO}_{\mathrm{ads}}+\mathrm{Pt}+\mathrm{H}^{+}+\mathrm{e} \\
& \mathrm{Pt}_{3} \equiv \mathrm{COH}_{\mathrm{ads}}+\mathrm{OH}^{-} \rightarrow \mathrm{Pt}_{2}=\mathrm{CO}_{\mathrm{ads}}+\mathrm{Pt}+\mathrm{H}_{2} \mathrm{O}+\mathrm{e} \\
& \mathrm{Pt}_{3} \equiv \mathrm{COH}_{\mathrm{ads}}+\mathrm{Pt}-\mathrm{OH}_{\mathrm{ads}} \rightarrow \mathrm{Pt}_{2}=\mathrm{CO}_{\mathrm{ads}}+2 \mathrm{Pt}+\mathrm{H}_{2} \mathrm{O} \\
& \mathrm{Pt}_{3} \equiv \mathrm{COH}_{\mathrm{ads}}+\mathrm{Pt}-\mathrm{OH}_{\mathrm{ads}} \rightarrow \mathrm{Pt}-\mathrm{CO}_{\mathrm{ads}}+3 \mathrm{Pt}+\mathrm{H}_{2} \mathrm{O}
\end{aligned}
$$

Regeneration of active sites through the processes involving $\mathrm{OH}$ species can just partly promote continuation of methanol adsorption and more importantly, it seems that this regeneration needs three adjacent sites with a C3v symmetry as a pre-requisite [22]. Therefore, dissociative adsorption of methanol should follow a self-feeding mechanism, where surface diffusion of adsorbates accompanies flow of electrons into external circuit and subsequent regeneration of vacant active sites. Surface diffusion of reaction intermediates has also been proposed in other research article [22], especially for interpretation of higher electrocatalytic activities of alloys compared to pure platinum. In this regard, although $\mathrm{CO}$ is known to strongly adsorb, its surface mobility on platinum and some of its alloys has been reported [23-25]. Indeed, this feedback is more clearly visualized through the "cleaning" of the surface according to the following reactions [13]:

$$
\begin{aligned}
& \mathrm{Pt}_{2}=\mathrm{CO}_{\mathrm{ads}}+\mathrm{Pt}-\mathrm{OH}_{\mathrm{ads}} \rightarrow \mathrm{PtCOOH} \text { ads }+2 \mathrm{Pt} \\
& \mathrm{Pt}-\mathrm{COOH}_{\mathrm{ads}}+\mathrm{Pt}-\mathrm{OH}_{\mathrm{ads}} \rightarrow 2 \mathrm{Pt}+\mathrm{CO}_{2}+\mathrm{H}_{2} \mathrm{O}
\end{aligned}
$$

Overall, the anodic oxidation of methanol on unmodified polycrystalline platinum seems to be coupling of the faradaic processes and surface transport of adsorbates. This is characteristically a non-linear and dissipative process, which must be influenced by feedback. Non-linearity, dissipation and feedback in a dynamic system are clearly represented in the logistic map [26]. Figure 3a and 3b present the current-charge (time derivative of charge vs. charge) dependencies obtained from the anodic half cycle voltammograms of Figure 1. In order to make comparative plots like those in Figure 3, it was necessary to normalize the logistic equation by setting $r=4$, and to normalize other quantities by dividing them by their maximum values. It has been observed that data was fitted the logistic differential equation quite well (with the correlation coefficient of 0.98), what indicates chaotic nature of the MEO dynamics. Chaotic switching in the oxidation of methanol carried out 
under the regime of cyclic voltammetry has already been observed by Schell and Cai [27]. Figures $4 \mathrm{a}$ and $4 \mathrm{~b}$ represent the current-charge dependencies of the cathodic half cycle measurements and the related attempted logistic equations. No fit has been observed. Apparently, in the cathodic half cycle the initial partial desorption of hydroxide ions surely promotes further dissociation and oxidation of methanol. However, in the further cathodic domains these two effects are no longer cooperative They are virtually independent and merely controlled by the potential itself with no feedback imposed by presence of one upon another. Consequently, no fit to the logistic equation with one degree of freedom is expected. MEO on polycrystalline platinum electrodes in both alkaline and acidic media seems to follow the non-linear electrocatalytic dynamics, which is characterized by regeneration of active sites in the course of an anodic potential sweep. This process complies with the logistic differential equation. It seems that the processes ensued in the cathodic half cycle of the potential sweep are not controlled by the feedback mechanisms and do not fit the logistic equation.
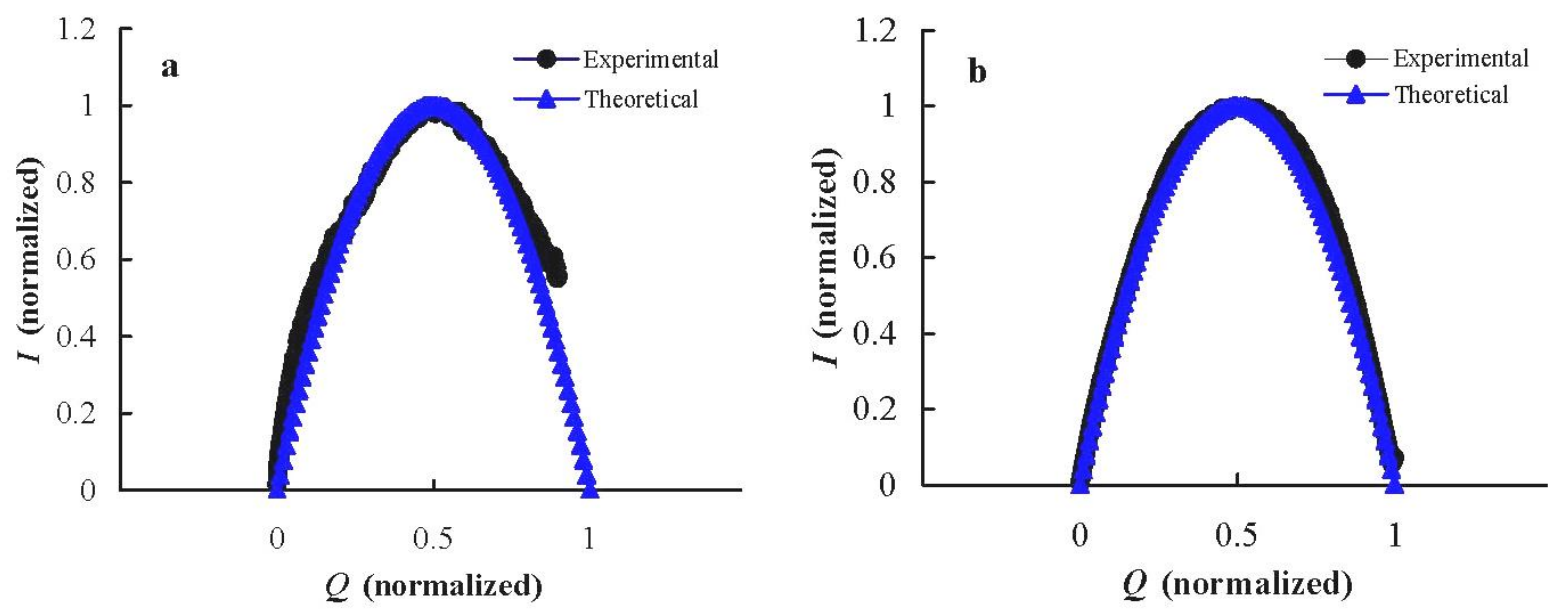

Figure 3. Time derivative of charge (current) vs. charge dependencies of the anodic half cycle voltammograms of MEO on polycrystalline Pt, normalized with respect to corresponding maximum values and theoretical curves: (a) acidic solution, (b) alkaline solution
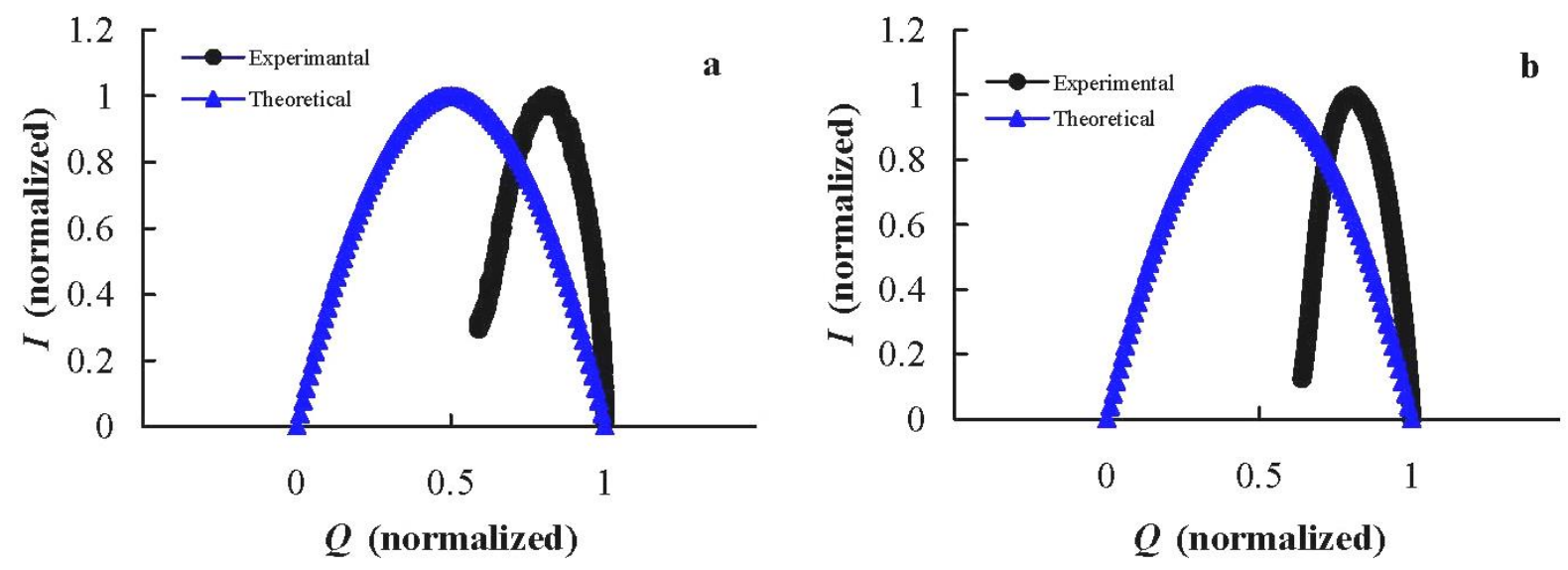

Figure 4. Current-charge dependencies of the cathodic half cycle voltammograms of MEO and the related logistic maps: (a) acid solution, (b) alkaline solution.

\section{Conclusion}

The electro-oxidation of methanol on platinum was analyzed by quadratic logistic equation indicating domination of two different behaviors in the anodic and cathodic (reverse) half cycles. In the anodic sweep, positive feedback controlled the reaction kinetics, while, the reverse sweep did 
not obey the logistic map. The results can be of importance in the analysis of the output of the hydrocarbon based fuel cells and the approach is expandable to other direct electrode processes.

\section{References}

[1] L. Lin, Q. Zhu, A. Xu, Prog. Chem. 27 (2015) 1147-1157.

http://dx.doi.org/10.1016/i.nanoen.2013.06.009

[2] H. Bahrami, A. Faghri, J. Power Sources 230 (2013) 303-320.

http://dx.doi.org/10.1016/i.jpowsour.2012.12.009

[3] H. Hoster, T. Iwasita, H. Baumgartner, W. Vielstich, Phys. Chem. Chem. Phys. 3 (2001) 337346. http://dx.doi.org/10.1039/B004895J

[4] W. F. Lin, P. A. Christensen, A. Hamnet, Phys. Chem. Chem. Phys. 3 (2001) 3312-3319. http://dx.doi.org/10.1039/B102699M

[5] Z. Tang, G. Lu, Prog. Chem. 19 (2007) 1301-1312. http://www.progchem.ac.cn/EN/Y2007/V19/19/1301

[6] J. M. Leger, J. Appl. Electrochem. 31 (2001) 767-771. http://dx.doi.org/10.1023/A:1017531225171

[7] H. Varela, R. M. Torresi, E. R. Gonzalez, Quim. Nova 25 (2002) 99-106. http://dx.doi.org/10.1590/S0100-40422002000100017

[8] R. M. Torresi, S. I. C. de Torresi, E. R. Gonzalez, J. Electroanal. Chem. 461 (1999) 161-166. http://dx.doi.org/10.1016/S0022-0728(98)00069-2

[9] E. R. Gonzalez, J. Electrochem. Soc. 143 (1996) L113-L115. http://dx.doi.org/10.1149/1.1836893

[10] S.N. Rasband, Chaotic dynamics of nonlinear systems, Wiley, New York, 1990.

[11] K. Malek, F. Gobal, Synth. Met. 113 (2000) 167-171. http://dx.doi.org/10.1016/S03796779(00)00194-6

[12] A. Bandura, American Psychologist 37 (1982) 747-755. http://psycnet.apa.org/doi/10.1037/0003-066X.37.7.747

[13] A. Hamnett, Catal. Today 38 (1997) 445-457. http://dx.doi.org/10.1016/S09205861(97)00054-0

[14] R. Manoharan, J. Prabhuram, J. Power Sources 96 (2001) 220-225. http://dx.doi.org/10.1016/S0378-7753(00)00683-2

[15] J. Lee, C. Eickes, M. Eiswirth, G. Ertl, Electrochim. Acta 47 (2002) 2297-2301. http://dx.doi.org/10.1016/S0013-4686(02)00075-0

[16] B.E. Conway, T.C. Liu, Langmuir 6 (1990) 268-276. http://dx.doi.org/10.1021/la00091a044

[17] S. Chen, M. Schell, J. Electroanal. Chem. 478 (1999) 108-117. http://dx.doi.org/10.1016/S0022-0728(99)00421-0

[18] R. Parsons, T. VanderNoot, J. Eelctroanal. Chem. 257 (1988) 9-45. http://dx.doi.org/10.1016/0022-0728(88)87028-1

[19] T. Iwasita, W. Vielstich, E. Santos, J. Electroanal. Chem. 229 (1987) 367-376. http://dx.doi.org/10.1016/0022-0728(87)85153-7

[20] B. Beden, F. Hahn, S. Juanto, C. Lamy, J. M. Leger, J. Electroanal. Chem. 225 (1987) 215-225. http://dx.doi.org/10.1016/0022-0728(87)80015-3

[21] S. Wasmus, A. Kuver, J. Electroanal. Chem. 461 (1999) 14-31. http://dx.doi.org/10.1016/S0022-0728(98)00197-1

[22] H. A. Gasteiger, N. Markovic, P.N. Ross, E. J. Cairns, J. Phys. Chem. 97 (1993) 12020-12029. http://pubs.acs.org/doi/abs/10.1021/i100148a030

[23] V. J. Kwasniewski, L. D. Schmidt, Surf. Sci. 274 (1992) 329-340.

http://dx.doi.org/10.1016/0039-6028(92)90838-W 
[24] T. Kobayashi, P. K. Babu, L. Gancs, J. H. Chung, E. Oldfield, A. Wieckowski, J. Am. Chem. Soc. 127 (2005) 14164-14165. http://dx.doi.org/10.1021/ja0550475

[25] P. K. Babu, J. H. Chung, S. T. Kuk, T. Kobayashi, E. Oldfield, A. Wieckowski, J. Phys. Chem. 109 (2005) 2474-2477. http://dx.doi.org/10.1021/jp040729k

[26] R. C. Hilborn, Chaos and Nonlinear Dynamics, Oxford University Press, Oxford, 2000.

[27] M. Schell, X. Cai, Electrochim. Acta 38 (1993) 519-527. http://dx.doi.org/10.1016/00134686(93)85007-L

2016 by the authors; licensee IAPC, Zagreb, Croatia. This article is an open-access article distributed under the terms and conditions of the Creative Commons Attribution license (http://creativecommons.org/licenses/by/4.0/) 